\title{
Dung beetles (Coleoptera: Scarabaeidae) can improve soil hydrological properties
}

\author{
Jacqueline Brown $^{\mathrm{a}, *}$, Clarke H. Scholtz ${ }^{\mathrm{a}}$, Jean-Louis Janeau ${ }^{\mathrm{b}}$, Seraphine Grellier ${ }^{\mathrm{b}}$, Pascal Podwojewski ${ }^{\mathrm{b}}$ \\ a Department of Zoology and Entomology, University of Pretoria, Lynnwood Road, Hatfield, Pretoria, Gauteng, 0002, South Africa \\ ${ }^{\mathrm{b}}$ Institut de Recherche pour le Developpement c/o School of Bioresources Engineering and Environmental Hydrology, University of KwaZulu-Natal, Scottsville, 3209, South Africa
}

\section{A R T I C L E I N F O}

\section{Article history:}

Received 26 January 2010

Received in revised form 24 May 2010

Accepted 26 May 2010

\section{Keywords:}

Bulk density

Erosion

Infiltration

Land degradation

Paracoprid beetles

Runoff

\begin{abstract}
A B S T R A C T
Although dung beetles are known to perform a multitude of ecosystem services, their effects on water infiltration, runoff, porosity, moisture and erosion of soil have never been thoroughly researched. Maintenance of these hydrological properties is important in agro-ecosystem functioning where overgrazing results in negative impacts on the soil. The study site was located in the Potshini catchment in KwazuluNatal (South Africa), an area heavily grazed by livestock. We conducted two rainfall simulations on three $1 \mathrm{~m}^{-2}$ control (no dung) and six dung-treated plots in December 2008, and repeated the study in June 2009 on the same plots. Natural populations of dung beetles were allowed to colonise the dung. Simulations were conducted for $30 \mathrm{~min}$ at an intensity of $30 \mathrm{~mm} \mathrm{~h}^{-1}$. Key variables calculated were pre-runoff amounts $(\mathrm{Pi})$, infiltration ratios $(\mathrm{Ki})$, and soil losses. Samples were collected for bulk density determination during the same time periods in order to measure differences in porosity and moisture in control and dung-treated plots at different depths. Using multivariate statistics we found significant differences between dung-treated and control plots in three of four simulations. After $48 \mathrm{~h}$ of beetle activity, $\mathrm{Pi}$ and $K i$ values were significantly increased and remained at elevated levels six months later. Soil losses were initially higher in dung-treated plots than controls, but had declined to less than control values after six months. Bulk density in the A-horizon $(0-10 \mathrm{~cm})$ was significantly reduced after $48 \mathrm{~h}$ of beetle activity and remained so for six months. No difference in bulk density was observed at greater depths. Soil moisture initially increased significantly in the A-horizon, as well as at 20 and $30 \mathrm{~cm}$ depths after six months of activity. We conclude that dung beetles positively influence hydrological properties of the soil by increasing water infiltration and soil porosity, and reducing surface water runoff. Contrasting effects on soil losses are problematic to reconcile from this study. High losses initially observed may be offset in the long-term by reductions associated with the increased infiltration ratios, though this remains to be confirmed.
\end{abstract}

(C) 2010 Elsevier B.V. All rights reserved.

\section{Introduction}

Southern Africa has approximately 650 species of dung beetles, of which paracoprid (tunnelling) dung beetles comprise about 70 percent (Davis et al., 2008). They bury dung in tunnels excavated beneath dung pads that range from 10 to $103 \mathrm{~cm}$ in depth depending on the species (Edwards and Aschenborn, 1987). The dung is utilised as a medium for feeding and reproduction. Beetles either feed on the dung fluids or use the whole dung as food provisions for their larvae. Dung is buried in a chamber at the end of the burrow and either simply packed where it can be fed on or an egg is laid in it, or made into a ball onto which an egg is laid (Fincher, 1981). Beetle larvae remain in the soil from a few weeks to months before emerging as adults (Halffter and Edmonds, 1982). During peak activity in the summer months (October to February), the beetles may bury

\footnotetext{
* Corresponding author. Tel.: +27 714923920.

E-mail address: jbrown@zoology.up.ac.za (J. Brown).
}

entire dung pads within a few hours leaving no trace behind except excavated soil in their wake (Waterhouse, 1974). Beetles compact the soil on the tunnel sides and in their brood chambers, and leave a lightly packed back-fill of soil behind them as the tunnel progresses. Thus the only soil at the surface is that generated to initiate the excavation (Halffter and Edmonds, 1982). The amount of soil brought to the surface is proportional to the size of the beetle. High numbers of beetles are involved with more than 7000 individuals counted in a single elephant dung pat in the Kruger National Park in South Africa (Waterhouse, 1974).

Dung beetles provide numerous ecosystem services, many of which have been well studied and published in the literature. Most studies have focussed on services that are beneficial to the functioning of agro-ecosystems (Fincher, 1981; Losey and Vaughan, 2006; Nichols et al., 2008). The results of their tunnelling and dung burial are known to increase plant yield as well as the percentage of nitrogen content in pasture herbage (Waterhouse, 1974; Bang et al., 2005). Dung that is rapidly buried by beetles loses only 5-15\% of its nitrogen, while volatilization results in the loss of $80 \%$ of nitrogen if 
dung remains on the soil surface (Gillard, 1967). Their high rates of dung disposal by breaking up and burying dung have been shown to reduce the survival of livestock insect pests that breed in dung (Bornemissza, 1970; Waterhouse, 1974; Doube, 1986; Edwards and Aschenborn, 1987) and reduce the effects of pasture fouling due to the presence of dung pads (MacLusky, 1960). The emphasis on these services is justified, as the extensive treatment of livestock with veterinary parasiticides in agro-ecosystems can negatively impact on dung beetle communities (Floate et al., 2004). In addition, habitat modification of grasslands by grazing livestock alters soil temperature, moisture levels and vegetation density which leads to changes in dung beetle community structure (Davis et al., 2004).

It has also been implied that dung beetles improve water infiltration in soil, (Waterhouse, 1974; Bang et al., 2005), although to date this effect has not been convincingly shown. In a comprehensive review of the ecosystem services provided by dung beetles, Nichols et al. (2008) highlighted the need for further research into the physical effects of dung beetles on soil structure. Ranging in width from 1 to $50 \mathrm{~mm}$, their simple and compound tunnels create macro-pores relative to their body size in the soil (Halffter and Edmonds, 1982) that theoretically influence infiltration ratios, porosity, soil moisture and aeration, and reduce surface water runoff. Based on studies that have shown how subterranean activity by termites (Elkins et al., 1986; Léonard et al., 2004) and ants (Wang et al., 1996) has increased infiltration ratios and reduced runoff, we can reasonably expect similar results from dung beetles. Reduced porosity and infiltration are characteristic of degraded soils as a result of vegetation removal through overgrazing, and improvements to these properties enhance plant growth thereby aiding in soil restoration (Snyman and Du Preez, 2005). While improved infiltration ratios lead to reduced soil loss, soil excavated to the surface from tunnelling beetles is likely to be exported during rainfall events making their overall influence on soil loss difficult to predict.

The objectives of this study were to: (i) test the influence of dung beetles on water infiltration ratios, runoff, porosity and soil loss. This was done using standardised rainfall simulations on soil to which dung had been added to attract beetles, and comparing results with soil to which no dung had been added; (ii) establish the duration of effects with repeated rainfall simulations on the same plots six months later; (iii) compare soil porosity and moisture during the same time periods by measuring bulk density in the presence and absence of dung beetles.

\section{Materials and methods}

\subsection{The study area}

Sampling and rainfall simulations were carried out in the Potshini Catchment area $\left(10 \mathrm{~km}^{2}\right)$ in the foothills of the Drakensberg mountains, Kwazulu-Natal, South Africa ( $28^{\circ} 48^{\prime} 37^{\prime \prime} \mathrm{S}, 29^{\circ} 21^{\prime} 19^{\prime \prime} \mathrm{E}$; elevation $1285 \mathrm{~m}$ a.s.l.). The vegetation in the area is Northern Kwazulu-Natal moist grassland (Mucina and Rutherford, 2006) which is being transformed by livestock farming practices into savannoid woodland by encroaching trees, mainly Acacia sieberiana var. woodii. Small-scale farmers utilise the area for grazing cattle and goats. Heavy grazing also exacerbates the already naturally eroded slopes of the undulant topography.

The dominant soil type is a Luvisol which originates from colluvium parent-rock of different origins (W.R.B., 1998). Based on three soil profile observations, the A-horizon is $15-18 \mathrm{~cm}$ thick with a fine granular structure and a sandy loam texture. The clay content increases from $20 \%$ at the soil surface to over $40 \%$ at $50 \mathrm{~cm}$ depth in the Bt-horizon which has a very clear coarse blocky structure. The climate is sub-tropical humid and the catchment falls within the summer (October to March) rainfall area. At the town of Bergville,
$10 \mathrm{~km}$ to the North, the mean annual precipitation over the last 30 years was $684 \mathrm{~mm}$ with a mean annual temperature of $13^{\circ} \mathrm{C}$ (Schulze, 1997). The average rainfall intensity in the Drakensberg area is $30 \mathrm{~mm} \mathrm{~h}^{-1}$ (Nel and Sumner, 2007).

\subsection{Rainfall simulations}

\subsubsection{Preparation of plots}

A total of nine $1 \mathrm{~m}^{2}$ steel plot frames were embedded approximately $5 \mathrm{~cm}$ into the soil surface, $6 \mathrm{~m}$ apart (Janeau et al., 2003). The plots were set out in three rows of three with two dungtreated and one control plot per row, giving a total of six treated plots and three controls. On all plots the proportion of vegetation cover and number of grass tufts were estimated. These variables were initially included in multivariate analyses, but were excluded from the final analysis as they had low factor loadings in the PCA and explained very little variation between the plots. Vegetation (grasses and forbs) was then cut to ground level to minimise the effect of rainfall interception and the angle of slope was averaged at $6.6 \%$. An area of $3 \mathrm{~m}^{2}$ including each plot was evenly wet with $50 \mathrm{~mm}$ of water one day prior to simulations in order to standardise antecedent soil moisture levels. The plots were fenced to protect them from interference by livestock. In December 2008 a mixture of $70 \%$ cattle and $30 \%$ pig dung was used to make $1 \mathrm{~kg}$ wet weight (average $180 \mathrm{~g}$ dry weight) standardised dung pats, three of which were placed in the same diagonal arrangement on each of the dungtreated plots. Natural populations of dung beetles were then able to colonise the dung. Each dung pat was approximately $20 \mathrm{~cm}$ in diameter and all three pats were calculated to cover approximately $0.09 \mathrm{~m}^{2}$. Dung pat size, quantity and arrangement were selected to simulate a single defecation by wandering cattle in a natural setting where they deposit about $2.5 \mathrm{~kg}$ of faeces between 10 and 24 times a day in one large, or several smaller pats (Rosenberger et al., 1977). Bornemissza (1960) found that the average area that grass-fed cattle covered in dung was $1 \mathrm{~m}^{2}$ per day. Dung of any kind attracts a mix of species and individual dung pats may have differential attraction for reasons including the degree of moisture, pat size, pat position and nutritional composition (Barth et al., 1994). The limited number of pats used in this study may have attracted low numbers of beetles, so a mixture of cattle and pig dung was used to give the best representivity of beetle species in the area. No dung was placed on the control plots. One natural rainfall event occurred during the simulations in December and for the duration of this rainfall a $3 \mathrm{~m}^{2}$ area including the plots was completely protected with PVC sheeting.

\subsubsection{Simulation procedure}

Simulations were conducted in December 2008 after dung application, and repeated on the same plots in June 2009 without the further application of dung to measure the duration of effects. Simulations using equipment and methods developed by Asseline and Valentin (1978) were used to determine infiltration ratios, pre-runoff amounts and soil losses by generating artificial rain with controlled parameters (intensity and duration) over each plot. These were essentially the following: a $4 \mathrm{~m}$ high metal frame covered in plastic sheeting was assembled and positioned over one plot at a time. A sprinkler nozzle mounted at the top of the structure delivered a measured amount of 'rain' to each plot centred within a $3 \mathrm{~m}^{2}$ area. Dung beetles were expected to have buried most of the dung within two days of placement (Waterhouse, 1974; Kruger et al., 1998), but it was unknown whether the full extent of their underground tunnelling would have been attained within this time or was continued for a longer period. Therefore, each plot received two successive rainfall simulations 48 and $72 \mathrm{~h}$ after dung application in order to assess any variation in effects after visible surface activity had ceased. As it was only possible to treat three plots per 
day, one row of three plots was completed each day for a total of six days for the two simulations. Each simulation was carried out at an intensity of $30 \mathrm{~mm} \mathrm{~h}^{-1}$ for $30 \mathrm{~min}$. The same rainfall intensity was used in June 2009 with two rainfall simulations conducted $24 \mathrm{~h}$ apart. This enabled a comparison to be made with results from December 2008 where any changes in parameters over the $24 \mathrm{~h}$ period may have been due to continued beetle activity or as a result of changes associated with the first rainfall simulation like differing antecedent moisture levels. The down-slope side of the plot was installed so that holes in the steel were flush with the soil surface and runoff water could flow via a gutter into a PVC pipe for collection in $500 \mathrm{ml}$ bottles.

Pre-runoff amounts $(P i, \mathrm{~mm})$ were calculated as $P i=w i+S i$ where wi $(\mathrm{mm})$ is the cumulative depth of water that infiltrates into the soil at time $t i$; and $S i(\mathrm{~mm})$ is the depth of accumulated water at the surface during the pre-runoff stage (Podwojewski et al., 2007). Soil surface and moisture conditions prior to rainfall can affect $P i$ rates.

The difference between rainfall $(\mathrm{mm})$ and runoff $(\mathrm{mm})$ was calculated as the total infiltrated rain. Infiltration ratios $(\mathrm{Ki})$ were calculated as a ratio $K i=\left(S L_{i} / S P_{u}\right) \times 100$ where $S L_{i}$ is the total infiltrated rainfall depth and $S P_{u}$ is the total rainfall depth (Casenave and Valentin, 1992).

\subsection{Soil loss}

Following the methods described by Gee and Bauder (1986) for grain size analysis, the soil in each $500 \mathrm{ml}$ bottle was obtained by evaporating the water in beakers on hot plates and mineralising any organic matter with the addition of $\mathrm{H}_{2} \mathrm{O}_{2}$. This was done to eliminate the mass of organic matter that may have been higher on plots where dung had been applied. In this way, sediment losses alone were compared. The soil was then weighed and the combined weight from all the samples provided the total soil loss $\left(\mathrm{g} \mathrm{m}^{-2}\right)$ for each plot. The sediment concentration $\left(\mathrm{g} \mathrm{L}^{-1}\right)$ was also calculated but was not included in multivariate analyses as its calculation is dependent on soil losses.

\subsection{Soil bulk density and moisture}

Soil samples for bulk density determination were collected in December 2008 and June 2009 following different protocols. In both instances the core method of sampling described by Blake and Hartge (1986) was followed using a $250 \mathrm{~cm}^{-3}$ metal cylinder. Bulk density samples were also used to calculate soil moisture gravimetrically.

Initial sampling involved the placement of six $1 \mathrm{~kg}$ dung pats adjacent to the site of the established plots. A mixture of $70 \%$ cattle and $30 \%$ pig dung was used for the pats. These were arranged in two rows of three dung pats with a third row of three control sites where no dung was placed. Natural populations of dung beetles colonised the pats and three samples of the top $10 \mathrm{~cm}$ of soil were collected from beneath three dung pats, two days and five days after dung placement, as well as from the control sites.

Samples obtained in June were from the actual plots after rainfall simulations had been completed. In each of the plots, three samples were taken at depths of $0-10 \mathrm{~cm}, 10-20 \mathrm{~cm}$, and $20-30 \mathrm{~cm}$. These were taken from three locations corresponding to the original placement of the dung pats on the dung-treated plots. Samples from control plots were obtained in the same pattern. All samples were weighed to obtain the wet weight and then oven-dried at $105^{\circ} \mathrm{C}$ for $72 \mathrm{~h}$ and re-weighed to determine dry weight. Soil moisture was calculated in $\mathrm{g} \mathrm{kg}^{-1}$ related to soil dry mass using methods described by Garten (1986).

\subsection{Data analysis}

\subsubsection{Rainfall simulations}

A generalized linear mixed model (GLMM) using a logarithmic link function was selected to establish the effect of treatment, time and interaction effects on $P i, K i$, sediment concentration and soil loss on the plots. Selection was based on the unbalanced design and repeated measures used in this study (Quinn and Keogh, 2006). Analysis was completed using SPSS Version 17.

With no a priori presumptions of sample relationships, multivariate analyses were used to detect groupings in the data using a principal components analysis (PCA). The PCA was based on product-moment correlation co-efficients (McGarigal et al., 2002). In order to assess the integrity of the identified groups, a posteriori analysis was used that maximised the variation between groups and minimised variation within groups. To test for statistically significant differences between the groups, discriminant analysis was used followed by a multivariate analysis of variance (MANOVA) (McGarigal et al., 2002). Analyses were undertaken using algorithms in Statistica Version 8 (StatSoft, Inc. Tulsa OK). The three variables used were pre-runoff amounts $(\mathrm{Pi})$, infiltration ratios $(\mathrm{Ki})$ and soil losses.

In all analyses the results of the first rainfall were analysed separately to those from the second for each simulation period in order to avoid effects of temporal pseudo-replication (Hurlbert, 1984).

\subsubsection{Soil bulk density and moisture}

The data were analysed using descriptive univariate statistics and were examined prior to analysis to ensure the assumptions of homogeneity of variance and normality were met. Samples obtained in December 2008 were analysed with a one-way analysis of variance (ANOVA) using two days, five days and control as fixed factors. A Tukey's HSD post hoc test was used to compare group means between factors. Samples taken in June 2009 were analysed with a multifactor ANOVA (Quinn and Keogh, 2006). The crossed factors in analysis were depth $(0-10 ; 10-20 ; 20-30 \mathrm{~cm})$ and treatment (control and dung-treated) and main as well as interaction effects were analysed. All statistical analyses were completed using Statistica Version 8 (StatSoft, Inc. Tulsa OK).

\section{Results}

Within minutes of dung placement on the plots, dung beetles rapidly flew in from surrounding areas and orientated to the pats. They immediately began feeding on the dung and burrowing into the soil taking dung with them. The dung pats appeared to be in continuous motion while beetles were active. After $48 \mathrm{~h}$ of activity all that remained at the surface was loose, excavated soil where the dung had been and a thin, dry crust of dung above this. Many holes from 2 to $15 \mathrm{~mm}$ wide were clearly visible at the soil surface after excavated soil and remaining dung had been partially washed away after the first rainfall simulation. A similar pattern was observed at all dung pats placed during the study. After initial rainfall simulations, the re-growth of vegetation on dung-treated plots was noticeably thicker and higher than on the controls. But when re-cut to ground level in June 2009 there was no obvious difference in the vegetation cover between the plots.

\subsection{Rainfall simulations}

The pre-runoff amounts were significantly higher on dungtreated than control plots after $48 \mathrm{~h}$ of activity and the difference was sustained for six months $(P=0.006)$ (Fig. 1a). Pre-runoff amounts on controls remained at a similar level over time ranging from a mean of $1.2 \mathrm{~mm} \pm 0.53$ to $2.15 \mathrm{~mm} \pm 0.94$. They were 

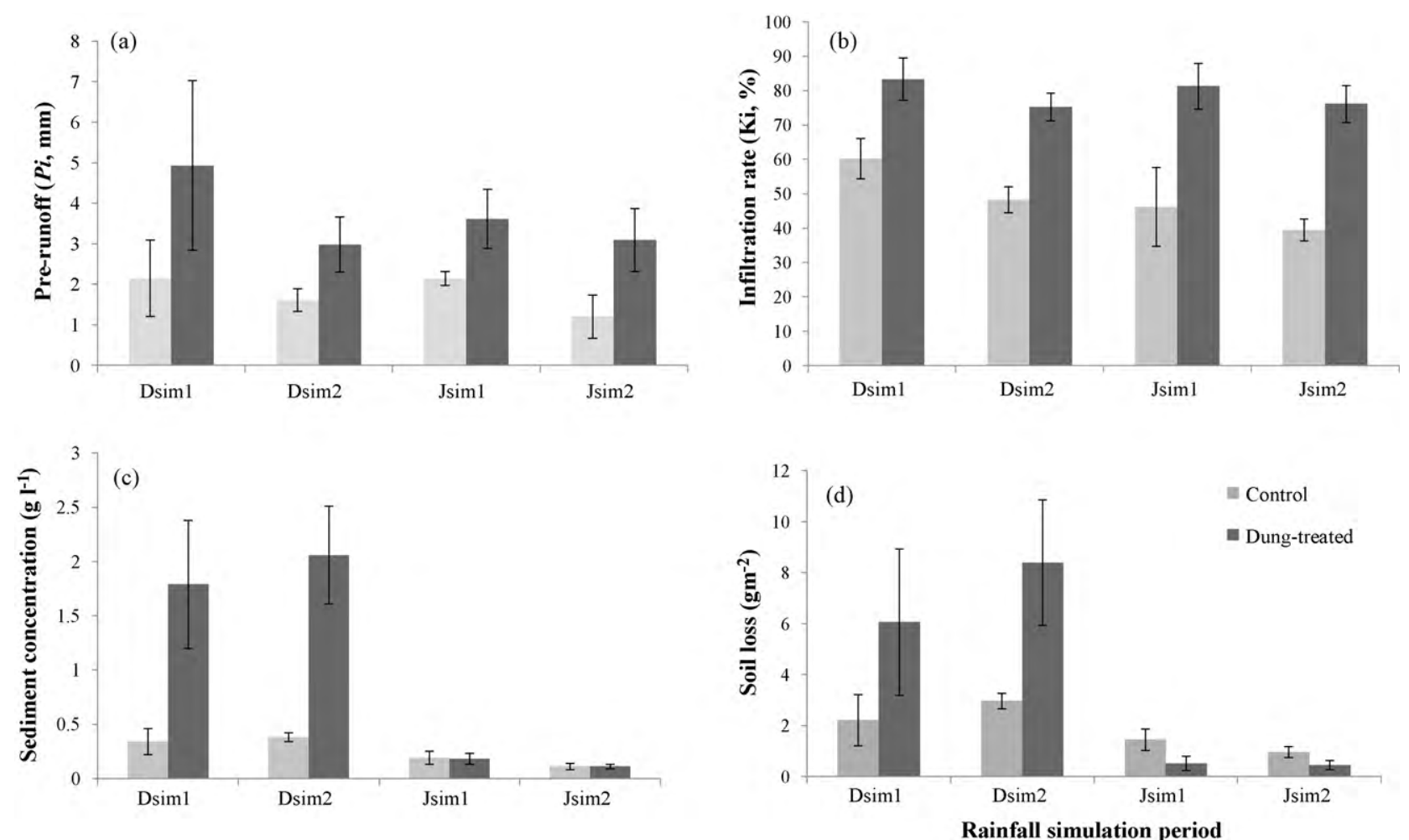

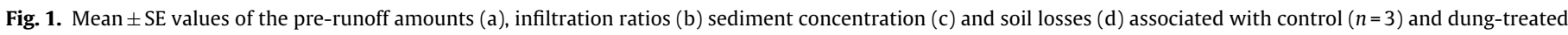
$(n=6)$ plots during two rainfall simulations in December 2008 (Dsim1 and Dsim2) and June 2009 (Jsim1 and Jsim2).

\section{Table 1}

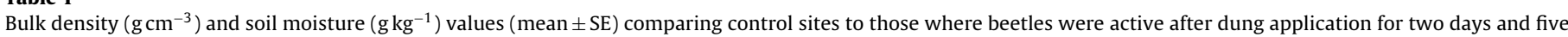
days respectively.

\begin{tabular}{|c|c|c|c|c|}
\hline & Control: C & Two days of beetle activity: 2 & Five days of beetle activity: 5 & $F^{\dagger}$ \\
\hline Bulk Density $\left(\mathrm{g} \mathrm{cm}^{-3}\right)$ & $1.34 \pm 0.03^{2,5}$ & $1.23 \pm 0.0^{C}$ & $1.23 \pm 0.0^{C}$ & $F_{2,24}=5.74^{* *}$ \\
\hline Moisture $\left(\mathrm{g} \mathrm{kg}^{-1}\right)$ & $151.91 \pm 4.67^{2,5}$ & $203.90 \pm 7^{C}$ & $202.09 \pm 4.9^{C}$ & $F_{2,24}=25.42^{* * *}$ \\
\hline
\end{tabular}

Values differed significantly to treatments in superscript ( $C$ = control, 2 = two days, 5 = five days), (Tukey's HSD).

$\dagger$ One-way analysis of variance $(F)$.

**** $P<0.001$.

${ }^{* *} P<0.01$.

more variable on dung-treated plots ranging from $2.98 \mathrm{~mm} \pm 0.68$ to $4.93 \mathrm{~mm} \pm 2.09$.

The mean infiltration ratio on the dung-treated plots was significantly higher than controls after $48 \mathrm{~h}$ of dung beetle activity and during both simulations six months later $(P=<0.001)$ (Fig. 1b). Controls showed a decreasing trend over time with a significant difference between the first simulation in December and the second in June $(P=0.019)$. Mean infiltration ratios in the dungtreated plots ranged from $75.21 \% \pm 3.99(11.25 \mathrm{~L}$ infiltrated) to $83.31 \% \pm 6.16$ ( $12.4 \mathrm{~L}$ infiltrated). By comparison, mean infiltration ratios in the control plots ranged from $39.4 \% \pm 3.19(5.9 \mathrm{~L}$ infiltrated) to $60.22 \% \pm 5.83$ (10.2 L infiltrated).

Sediment concentrations differed significantly between control and dung-treated plots $(P=<0.001)$ as well as over time
$(P=<0.001)$. Mean sediment concentration was significantly higher in dung-treated plots than controls during both simulations in December 2008 (Fig. 1c) and decreased in dung-treated plots and controls from December to June when differences between treatments were not significant.

While the pattern of soil loss appeared similar to that of sediment concentration (Fig. 1d), the treatment effect was not significant. This was surprising as mean soil losses from dung-treated plots after 48 and $72 \mathrm{~h}$ were over double those from controls. However, there was a high amount of variation in dung-treated-plot results as observed in their large standard errors (Fig. 1d). Time had a significant overall effect $(P=<0.001)$ with higher soil losses on dung-treated plots in both December simulations than those in June. This was not

Table 2

Multifactor analysis of variance of the effect of beetles (treatment) and depth $(10,20,30 \mathrm{~cm})$ on bulk density and soil moisture six months after beetle activity.

\begin{tabular}{|c|c|c|c|c|c|c|c|}
\hline \multirow[b]{2}{*}{ Source } & \multicolumn{4}{|c|}{ Bulk density } & \multicolumn{3}{|c|}{ Soil moisture } \\
\hline & d.f. & MS & $F$ & $P$ & MS & $F$ & $P$ \\
\hline Treatment: T & 1 & 0.06 & 8.66 & 0.004 & 251.28 & 40.02 & $<0.001$ \\
\hline Depth: D & 2 & 0.14 & 18.71 & $<0.001$ & 146.47 & 23.33 & $<0.001$ \\
\hline $\mathrm{T} \times \mathrm{D}$ & 2 & 0.04 & 5.8 & 0.005 & 3.26 & 0.51 & 0.597 \\
\hline Residual & 75 & 0.01 & & & 6.28 & & \\
\hline
\end{tabular}


Table 3

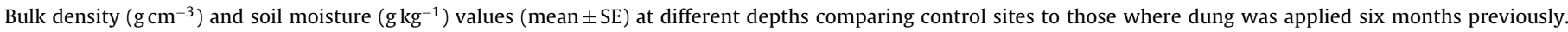
Superscript letters associated with mean values indicate significant differences between means of $P<0.05(C=$ control, $D=$ dung-treated, $10,20,30=\mathrm{cm}$ depth).

\begin{tabular}{|c|c|c|c|}
\hline & Soil depth & Control: C & Six months after dung application: D \\
\hline Bulk Density $\left(\mathrm{g} \mathrm{cm}^{-3}\right)$ & $\begin{array}{l}10 \mathrm{~cm} \\
20 \mathrm{~cm} \\
30 \mathrm{~cm}\end{array}$ & $\begin{array}{l}1.38 \pm 0.04^{\mathrm{D} 10} \\
1.45 \pm 0.02^{\mathrm{D} 10} \\
1.43 \pm 0.03^{\mathrm{D} 10}\end{array}$ & $\begin{array}{l}1.23 \pm 0.0^{\mathrm{C} 10 ; \mathrm{C} 20 ; \mathrm{C} 30 ; \mathrm{D} 20 ; \mathrm{D} 30} \\
1.41 \pm 0.02^{\mathrm{D} 10} \\
1.45 \pm 0.02^{\mathrm{D} 10}\end{array}$ \\
\hline Soil moisture $\left(\mathrm{g} \mathrm{kg}^{-1}\right)$ & $\begin{array}{l}10 \mathrm{~cm} \\
20 \mathrm{~cm} \\
30 \mathrm{~cm}\end{array}$ & $\begin{array}{l}181.42 \pm 15.8^{\mathrm{C} 20 ; \mathrm{C} 30} \\
145.65 \pm 8.8^{\mathrm{C} 10 ; \mathrm{D} 10 ; \mathrm{D} 20 ; \mathrm{D} 30} \\
129.59 \pm 10.2^{\mathrm{C} 10 ; \mathrm{D} 10 ; \mathrm{D} 20 ; \mathrm{D} 30}\end{array}$ & $\begin{array}{l}209.79 \pm 4.3^{\mathrm{C} 20 ; \mathrm{C} 30 ; \mathrm{D} 20 ; \mathrm{D} 30} \\
177.07 \pm 4.7^{\mathrm{C} 20 ; \mathrm{C} 30 ; \mathrm{D} 10} \\
171.27 \pm 3.1^{\mathrm{C} 20 ; \mathrm{C} 30 ; \mathrm{D} 10}\end{array}$ \\
\hline
\end{tabular}

reflected in control plots which did not significantly differ over time.

\subsection{Bulk density and soil moisture}

The December 2008 ANOVA showed that mean bulk density in the control sites was significantly higher than sites with beetles (Table 1). The Tukey's HSD test established a significant difference between the control sites and sites where beetles were active for two days and five days. There was no difference in the results between the sites after two and five days which is reflected in their identical mean values. Similar results were observed for soil moisture values that were significantly higher in the dung-treated than control plots, and again there was no difference between two and five days.
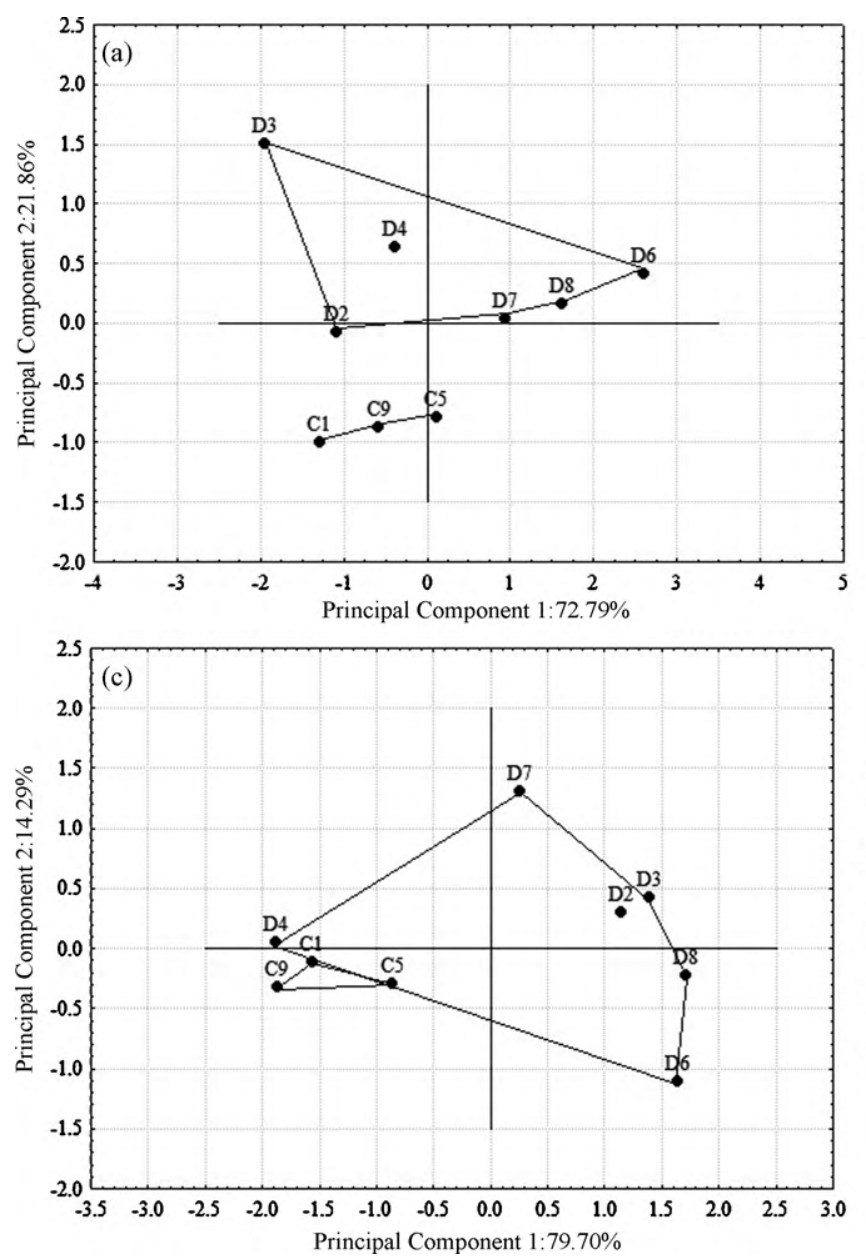

Results of the multifactor ANOVA for bulk density and soil moisture in June 2009 are presented in Table 2 along with mean values and Tukey's HSD results in Table 3. There was a significant treatment effect with mean bulk density higher in the control plots than those where the beetles had been active six months earlier. The depth effect was also significant with lower bulk density in the first $10 \mathrm{~cm}$ of soil in both dung-treated and control plots than at greater depths of $10-20$ and $20-30 \mathrm{~cm}$. The interaction between depth and treatment was significant, reflecting the fact that the effect of beetle activity was confined to the top $10 \mathrm{cms}$. Mean bulk density values at $0-10 \mathrm{~cm}$ on dung-treated sites were exactly the same after five days of beetle activity in December 2008 (Table 1) as they were six months later in June 2009 on the dung-treated plots (Table 3). A similar trend was observed in the control plots.

The multifactor ANOVA showed significant effects of treatment and depth on soil moisture results but no interaction effect
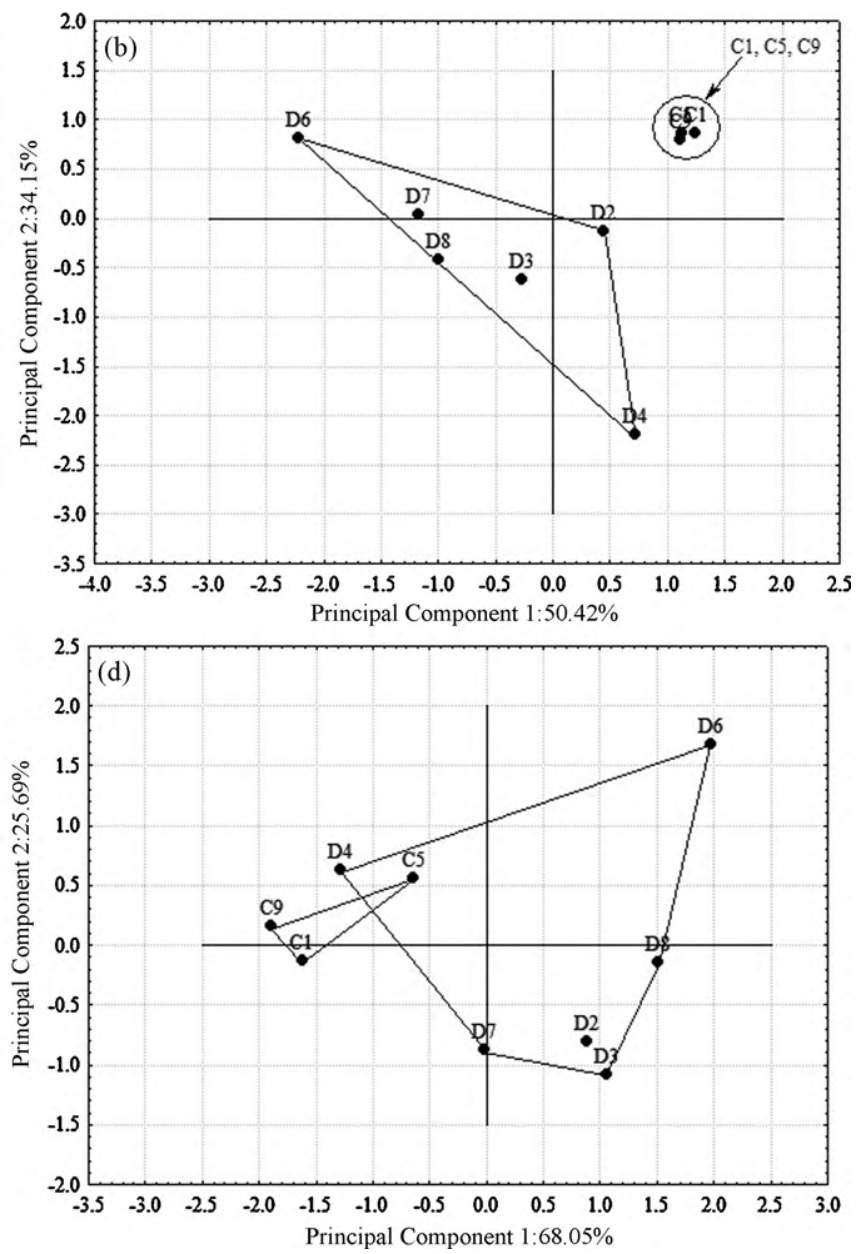

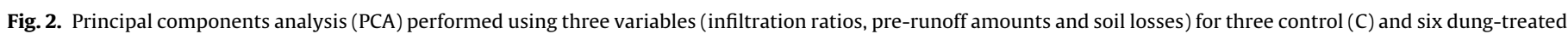
(D) plots after two rainfall simulations in December 2008 ( $\mathrm{a}$ and b) and June 2009 ( $\mathrm{c}$ and d). Principal component axes one and two are plotted. 
Table 4

Factor loadings of the three variables in principal component I and II (PC I and PC II) from the principal components analysis (PCA) shown in Fig. 2.

\begin{tabular}{|c|c|c|c|c|c|c|c|c|}
\hline \multirow[b]{2}{*}{ Variable } & \multicolumn{2}{|c|}{ December Rain 1} & \multicolumn{2}{|c|}{ December Rain 2} & \multicolumn{2}{|c|}{ June Rain 1} & \multicolumn{2}{|c|}{ June Rain 2} \\
\hline & PC I & PC II & PC 1 & PC II & PC I & PC II & PC I & PC II \\
\hline Pre-runoff & 0.94 & 0.13 & -0.87 & 0.09 & 0.84 & -0.53 & 0.61 & 0.79 \\
\hline Infiltration & 0.87 & 0.41 & -0.85 & -0.22 & 0.90 & 0.34 & 0.90 & -0.30 \\
\hline Soil loss & -0.72 & 0.68 & 0.11 & -0.98 & -0.93 & -0.14 & -0.92 & 0.22 \\
\hline \% Trace & 72.79 & 21.86 & 50.42 & 34.15 & 79.70 & 14.29 & 68.05 & 25.69 \\
\hline
\end{tabular}

(Table 2). Mean soil moisture was significantly higher in dungtreated plots than control plots at depths of 20 and $30 \mathrm{~cm}$ but not at $10 \mathrm{~cm}$ (Table 3). This is in contrast to results observed six months earlier where soil moisture was higher on dung-treated plots in the first $10 \mathrm{~cm}$ of soil (Table 1 ). Both control and dung-treated plots had significantly higher moisture values in the first $10 \mathrm{~cm}$ of soil than at 10 and $20 \mathrm{~cm}$ where results were very similar in both treatments.

\subsection{Principal components analysis}

Results of the PCA of rainfall simulations are presented in Fig. 2 and related factor loadings in Table 4 . After $48 \mathrm{~h}$ of beetle activity the dung-treated plots were clearly differentiated from the controls (Fig. 2a). Separation of the control and dung-treated plots was mainly along the second axis where the highest factor loading came from soil loss at 0.68 (Table 4 ) in the second principal component (PC II). After $72 \mathrm{~h}$ of activity the plots were even more distinctly separated with controls tightly clustered apart from dung-treated plots (Fig. 2b). The oblique angle of separation of the plots along both axes was due to high loadings of pre-runoff at -0.87 and infiltration at -0.85 in PC I, and soil loss at -0.98 in PC II (Table 4). The combined first and second principal components accounted for $94.65 \%$ and $84.58 \%$ of total variation in simulations after 48 and $72 \mathrm{~h}$ respectively (Table 4 ).

The distinction between control and dung-treated plots was clearly maintained in both rainfall simulations six months later, with the main difference being that dung-treated plot four clustered with the controls apart from the other dung-treated plots (Fig. 2c and d). Separation of the plots in the first simulation (Fig. 2c) was at an oblique angle along both axes driven by soil loss at -0.93 and infiltration at 0.90 in PC I, and pre-runoff at -0.53 in PC II (Table 4). Plots in the second simulation (Fig. 2d) mainly separated along the first axis with almost identical factor loadings to the first simulation of -0.92 from soil loss and 0.90 from infiltration in PC I. The first two principal components accounted for a total variation of $93.99 \%$ in the first simulation and $93.74 \%$ in the second (Table 4 ).

The discriminant analysis showed significant differences between dung-treated and control plots in all simulations except the first in June 2009 (Table 5). Results from the first simulation in June 2009 showed that most variables for dung-treated plot four were more similar to the mean values for the control plots (Fig. 1a, $\mathrm{b}$ and d) with an infiltration ratio of $50 \%$, soil loss of $1.89 \mathrm{~g} \mathrm{~m}^{-2}$ and a pre-runoff amount of $1.5 \mathrm{~mm}$. This was a contributing factor to the lack of a significant result in the discriminant analysis for this

\section{Table 5}

Discriminant analysis of three variables (pre-runoff amount, infiltration ratio and soil loss) on dung-treated and control plots after two rainfall simulations in December 2008 and June 2009.

\begin{tabular}{llrl}
\hline & d.f. & \multicolumn{1}{l}{$F$} & $P$ \\
\hline Dec. 2008 Simulation one & 5 & 8.31 & $0.021^{*}$ \\
Simulation two & 5 & 23.95 & $0.002^{* *}$ \\
Jun. 2009 Simulation one & 5 & 3.14 & 0.124 \\
Simulation two & 5 & 7.96 & $0.023^{*}$ \\
\hline${ }^{* *} P<0.01$. & & & \\
${ }^{*} P<0.05$. & & &
\end{tabular}

simulation and resulted in the grouping of the plot with controls in the PCA (Fig. 2b and d).

\section{Discussion}

There are three interesting findings in this study. The first is that after $48 \mathrm{~h}$ of dung beetle activity, pre-runoff amounts and infiltration ratios are increased and sustained at significantly higher levels for at least six months in a sandy loam soil type. The clear separation of control from dung-treated plots in the PCA results was influenced by infiltration ratios more often than pre-runoff values. The infiltration ratios showed less variation than pre-runoff which probably impacted on this result. Separation of the plots in both June PCAs was affected most strongly by soil losses and infiltration ratios. These results are important because the presence of remnant dung on the soil surface could be suspected of influencing our initial results. However, the sustained increase in pre-runoff and infiltration rates observed six months later, long after the crust of dung had disintegrated, indicate that any influence was minor. It is not known how long these improvements are maintained beyond six months, but increased infiltration ratios associated with termites were found to persist at similar levels for four years in sandy soil (Léonard et al., 2004). In addition, increased infiltration ratios and pre-runoff amounts were very similar over the duration of this study showing no indication of decreasing from initial levels six months later. Theoretically, the life cycle of paracoprid dung beetles is in itself a reinforcing process in maintaining these improvements because once the adults have tunnelled into the soil and deposited their eggs, the next generation of beetles will tunnel out of the soil and emerge weeks or months later (Halffter and Edmonds, 1982). However, it was not possible to confirm whether beetles in this study deposited eggs, and if or when any new beetles emerged.

The second finding is that dung beetles increase porosity in the A-horizon as shown by decreased bulk density in the first $10 \mathrm{~cm}$ of soil as well as the sustained higher pre-runoff amounts. This is the major zone of plant root development, and increased porosity and infiltration ratios are beneficial to plant growth by facilitating the supply of water and nutrients to roots and increasing aeration (Snyman, 2005). This is reflected in higher moisture levels in the A-horizon where beetles not only increase porosity but introduce organic matter (dung) with a higher moisture holding capacity. The lack of variation in bulk density and soil moisture results between 48 and $72 \mathrm{~h}$ after initial dung placement shows that the majority of subterranean beetle activity had taken place within the first $48 \mathrm{~h}$. Had beetle activity continued beyond this time, our results would have shown a continued increase in soil moisture and decrease in bulk density, but these results remained the same. The sustained lower bulk density in the A-horizon increases water infiltration to deeper layers of soil, again reflected in the higher moisture values observed at depths of 20 and $30 \mathrm{~cm}$ on dung-treated plots after six months. Presumably, the decay of introduced organic matter in the A-horizon leads to reduced soil moisture at this depth after six months. Bulk density is a reflection of soil porosity and is a useful parameter relating to ecosystem function. Low soil porosity results in restricted root growth, decreased aeration, and lower water infiltration ratios (F.A.O., 2006). In this respect, the refilled tunnels of 
a paracoprid dung beetle were observed by Brussaard and Hijdra (1986) to have higher porosity than surrounding soil leading to a higher concentration of plant roots in the tunnels themselves.

As dung beetles are known to tunnel to depths of $103 \mathrm{~cm}$ (Edwards and Aschenborn, 1987) it was noteworthy that bulk density was not affected at depths greater than $10 \mathrm{~cm}$. In a study assessing the biogeographical composition of dung beetle assemblages along an altitudinal gradient in the same province, tunnelling tribes were found to account for $86.6 \pm 9.6 \%$ abundance between 500 and $1500 \mathrm{~m}$ a.s.l. (Davis et al., 1999). Therefore a lack of tunnelling dung beetles in the community assemblage cannot be the reason. One possible explanation may be that bulk density samples in the first sampling period were only collected to $10 \mathrm{~cm}$ so there may have been an effect at deeper levels that was not observed or not sustained for six months. Secondly, beetles in the larger size classes are known to tunnel to greater depths than smaller individuals (Halffter and Edmonds, 1982) and very few large beetles ( $>20 \mathrm{~mm}$ wide) were observed at the site. In addition, the increased clay content in the Bt-horizon may have restricted beetle activity at depths beyond the A-horizon. Similar results to these findings were observed by Bang et al. (2005) who reported high air permeability of soil associated with three dung beetle species to a depth of $10 \mathrm{~cm}$, but no effect at $20 \mathrm{~cm}$.

The third interesting finding is that there is a high initial pulse of soil loss associated with soil excavated to the surface by the beetles. While not found to be statistically significant, this variable is positively correlated with sediment concentration which did show significant differences between treatments in December but not in June. Soil loss also had the highest loadings in three out of four of the PCAs, emphasising the role of this variable in differentiating treatments. There was no difference in either sediment concentration or soil losses between treatment plots in June, which confirms that the initial soil loss is temporary. While soil losses in June were slightly lower on dung-treated than control plots, this difference was not significant. This result was unforeseen as one could reasonably predict significantly reduced soil losses resulting from the sustained improvement in infiltration rates over time. Similar trends have been observed for other soil fauna like earthworms that improve infiltration rates and porosity, but deposit soil casts on the surface that contribute to soil losses (Blanchart et al., 2004). Unfortunately this study cannot provide a total comparative soil loss budget over time as it is impossible to say at what point during the six-month period the soil losses were reduced in the plots where beetles were active. Given that the infiltration ratios increased with immediate effect in association with dung beetles however, it is likely that once the initially excavated soil had been exported a sustained reduction in soil loss would be observed concurrently with increased infiltration ratios. This remains to be tested conclusively.

Close grouping of the control plots in all PCA results shows they were similar over the course of the study. There was consistent variation between the dung-treated plots as reflected in their more dispersed grouping in the PCAs. A large proportion of this variation is almost certainly due to diversity in the size distribution, abundance and extent of activity associated with natural populations of beetles. Beetles ranging in width from $<5 \mathrm{~mm}$ to $40 \mathrm{~mm}$ (one large Heliocopris sp.) were observed at the pats and this range conceivably reflects that of tunnel widths excavated by the beetles. While an estimate of the numbers of beetles per pat would have been helpful in explaining the variation in this study, this requires removal of the soil beneath the pat in order to count the beetles using the Berlese method (Kruger et al., 1998). The results of our study were dependent on the soil remaining undisturbed and as a result this could not be done. Factors like soil moisture levels have been shown to affect the depth to which beetles tunnel, with nests constructed at twice the depth in moist soil than in dry soil at the same location (Edwards, 1986). Variation in the location of tunnel entrances on the micro-topography of the plots could also influence infiltration ratios. While termites significantly increase infiltration ratios, the extent of their effects was also observed to vary and was attributed to seasonal and temperature-related changes in activity, and arbitrary re-filling of holes with soil transported during rain events (Léonard et al., 2004). During this study, no termite or ant activity was observed on the surface of any of the plots. While dung beetles were found in bulk density samples, no other significant soil fauna were observed, indicating a lack of other activity below the surface. We thus conclude that ants and termites made no contribution to the results obtained. Despite the low slope angle on the plots, it is conceivable that subterranean water may have moved downstream affecting antecedent moisture levels in plots. It is not possible to confirm whether the contrasting results observed on dung-treated plot four originated from biotic (beetles) or abiotic (soil) factors as there were no obvious surface differences. But the infiltration ratios may have been under-calculated as a result of a faulty connection between the PVC pipe and the gutter of the metal frame on that plot. As the vegetation was cut on all the plots exposing greater soil area, another factor that may have played a role in inter-plot variation is temperature related degrees of evaporation of infiltrated rain from the soil surface (Snyman, 1988). Particularly between the first and second simulation, this would influence antecedent moisture levels resulting in differences in subsequent pre-runoff amounts and infiltration ratios.

The main factors driving land degradation in communal areas in South Africa are overstocking and overgrazing (Harrison and Shackleton, 1999). Overgrazing leads to reduced vegetation cover and increased soil exposure which has been shown to result in high soil losses and compaction (Elkins et al., 1986). Along with termites (Léonard et al., 2004), dung beetles play a restorative role by improving the infiltration properties of crusted soils. This is important in mediating the effects of land degradation by reducing surface water runoff and improving plant growth and nutritional content (Bang et al., 2005). It is important to recall that dung beetle communities themselves are affected by overgrazing (Davis et al., 2004), so while they may mediate the effects of this process, there is likely to be a threshold beyond which their beneficial activities are reduced.

The application of these findings to other soil types is debatable. Dung beetle communities have been shown to differ across sand and clay soil types. While overall abundance does not differ, sandy soils are dominated by larger paracoprid beetles than clay soils (Davis, 1996). In well-drained sandy soils the management objective may be to reduce drainage in order to increase soil-water availability for plants, in which case tunnelling dung beetles may intensify porosity. However the introduction of organic matter (dung) into the soil is known to improve soil structure thereby enhancing water infiltration and reducing soil erosion (Thurow et al., 1986). The extrapolation of our results from $1 \mathrm{~m}^{-2}$ to a larger area where livestock are naturally grazing and depositing dung is complex. Cattle will congregate near feeding or watering areas, and otherwise disperse as they forage. Correspondingly their dung will occur in higher concentrations in some areas than others leading to variation in the effects of dung beetle activity on the soil.

While this study provides several valuable insights, opportunities for further research remain. Rainfall simulations offer limited scope for replication so infiltration ratios could be further investigated using tension or double ring infiltrometry at higher replications over a range of soil types and slopes. Long-term measures of soil losses at regular intervals could provide the basis for a soil loss comparison over time. While there are challenges relating economic values to water and soil, it may be possible to calculate the value of these ecosystem services after extrapolation to a larger spatial scale and consideration of the multitude of variables involved. 


\section{Acknowledgements}

Thanks to the S.A. National Research Foundation for funding, and to Prof. C.T. Chimimba for valuable suggestions on statistical analyses.

\section{References}

Asseline, J., Valentin, C., 1978. Construction et mise au point d'un infiltromētre à aspersion. Cah. Orstom, sér Hydrol. 14, 321-349.

Bang, H.S., Lee, J.H., Kwon, O.S., Na, Y.E., Jang, Y.S., Kim, W.H., 2005. Effects of paracoprid dung beetles (Coleoptera: Scarabaeidae) on the growth of pasture herbage and on the underlying soil. Appl. Soil Ecol. 29, 165-171.

Barth, D., Karrer, M., Heinze-Mutz, E.M., Elster, N., 1994. Colonization and degradation of cattle dung: aspects of sampling, fecal composition, and artificially formed pats. Environ. Entomol. 23, 571-578.

Blake, G.R., Hartge, K.H., 1986. Bulk density. In: Klute, A. (Ed.), Methods of Soil Analysis. Part 1. Physical and Mineralogical Methods. Agronomy Monograph No 9, Book Series , 2nd ed. Soil Science Society of America, Madison, WI, pp. 363-375.

Blanchart, E., Albrecht, A., Brown, G., Decaens, T., Duboisset, A., Lavelle, P., Mariani, L., Roose, E., 2004. Effects of tropical endogenic earthworms on soil erosion. Agric. Ecosyst. Environ. 104, 303-315.

Bornemissza, G.F., 1960. Could dung eating insects improve our pastures? J. Aust. Inst. Agric. Sci. 26, 54-56.

Bornemissza, G.F., 1970. Insectary studies on the control of dung breeding flies by the activity of the dung beetle, Onthophagus gazella F. (Coleoptera: Scarabaeinae). J. Aust. Entomol. Soc. 9, 31-41.

Brussaard, L., Hijdra, R.D.W., 1986. Some effects of scarab beetles in sandy soils of the Netherlands. Geoderma 37, 325-330.

Casenave, A., Valentin, C., 1992. A runoff capability classification system based on surface features criteria in semi-arid areas of West Africa. J. Hydrol. 130, 231-249.

Davis, A.L., Scholtz, C.H., Chown, S.L., 1999. Species turnover, community boundaries and biogeographical composition of dung beetle assemblages across an altitudinal gradient in South Africa. J. Biogeogr. 26, 1039-1055.

Davis, A.L.V., 1996. Community organisation of dung beetles (Coleoptera: Scarabaeidae): differences in body size and functional group structure between habitats. Afr. J. Ecol. 34, 258-275.

Davis, A.L., Scholtz, C.H., Dooley, C.H., Bham, N., Kryger, U., 2004. Scarabaeine dung beetles as indicators of biodiversity, habitat transformation and pest control chemicals in agro-ecosystems. S. Afr. J. Sci. 100, 1-10.

Davis, A.L., Frolov, A.V., Scholtz, C.H., 2008. The African Dung Beetle Genera. Protea Book House, Pretoria, South Africa.

Doube, B.M., 1986. Biological control of the buffalo fly in Australia: the potential of the southern African dung fauna. In: Patterson, R.S., Rutz, D.A. (Eds.), Biological Control of Muscoid Flies, vol. 61. Miscellaneous Publications of the Entomological Society of America.

Edwards, P.B., 1986. Phenology and field biology of the dung beetle Onitis caffer Boheman (Coleoptera: Scarabaeidae) in southern Africa. Bull. Entomol. Res. 76, 433-446.

Edwards, P.B., Aschenborn, H.H., 1987. Patterns of nesting and dung burial in Onitis dung beetles: implications for pasture productivity and fly control. J. Appl. Ecol. 24, 837-851.

Elkins, N.Z., Sabol, G.V., Ward, T.J., Whitford, W.G., 1986. The influence of subterranean termites on the hydrological characteristics of a Chihuahuan desert ecosystem. Oecologia 68, 521-528.

Fincher, G.T., 1981. The potential value of dung beetles in pasture ecosystems. J. Georgia Entomol. Soc. 16, 301-316.

Floate, K.D., Wardhaugh, K.G., Boxall, A.B.A., Sherratt, T.N., 2004. Fecal residues of veterinary parasiticides: nontarget effects in the pasture environment. Annu. Rev. Entomol. 50, 153-179.
Food and Agriculture Organisation of the United Nations, 2006. Guidelines for Soil Description. FAO, Rome, p. 50.

Garten, W.H., 1986. Water content. In: Klute, A. (Ed.), Methods of Soil Analysis. Part 1. Physical and Mineralogical Methods. Agronomy Monograph No 9, Book Series , 2nd ed. Soil Science Society of America, Madison, WI, pp. 493-544.

Gee, G.W., Bauder, J.W., 1986. Particle size analysis. In: Klute, A. (Ed.), Methods of Soil Analysis. Part 1. Physical and Mineralogical Methods. Agronomy Monograph No 9, Book Series , 2nd ed. Soil Science Society of America, Madison, WI, pp. 383-411.

Gillard, P., 1967. Coprophagous beetles in pasture ecosystems. J. Aust. Inst. Agric. Sci. 33, 30-34.

Halffter, G., Edmonds, W.D., 1982. The nesting Behaviour of Dung Beetles (Scarabaeinae): An Ecological and Evolutive Approach. Instituto de Ecología México D. F.

Harrison, Y.A., Shackleton, C.M., 1999. Resilience of South African communal grazing lands after the removal of high grazing pressure. Land Degrad. Dev. 10, 225-239.

Hurlbert, S.H., 1984. Pseudoreplication and the design of ecological field experiments. Ecol. Monogr. 54, 187-211.

Janeau, J.L., Briquet, J.P., Planchon, O., Valentin, C., 2003. Soil crusting and infiltration on steep slopes in northern Thailand. Eur. J. Soil Sci. 54, 1-11.

Kruger, K., Scholtz, C.H., Reinhardt, K., 1998. Effects of the pyrethroid flumethrin on colonisation and degradation of cattle dung by adult insects. S. Afr. J. Sci. 94 130-133.

Léonard, J., Perrier, E., Rajot, J.L., 2004. Biological macropores effect on runoff and infiltration: a combined experimental and modelling approach. Agric. Ecosyst. Environ. 104, 277-285.

Losey, J.E., Vaughan, M., 2006. The economic value of ecological services provided by insects. BioScience 56, 311-315.

MacLusky, D.S., 1960. Some estimates of the areas of pasture fouled by excreta of dairy cows. Grass For. Sci. 15, 181-188.

McGarigal, K., Cushman, S., Stafford, S., 2002. Multivariate Statistics for Wildlife and Ecology Research. Springer-Verlag, New York, USA.

Mucina, L., Rutherford, M.C. (Eds.), 2006. The vegetation of South Africa, Lesotho and Swaziland. Strelitzia 19. South African National Biodiversity Institute, Pretoria RSA.

Nel, W., Sumner, P.D., 2007. Intensity, energy and erosivity attributes of rainstorms in the KwaZulu-Natal Drakensberg, South Africa. S. Afr. J. Sci. 103, 398-402.

Nichols, E., Spector, S., Louzada, J., Larsen, T., Amezquita, S., Favila, M.E., 2008. Ecological functions and ecosystem services provided by Scarabaeinae dung beetles. Biol. Cons. 141, 1461-1474.

Podwojewski, P., Janeau, J.L., Leroux, Y., 2007. Effects of agricultural practices on the hydrodynamics of a deep tilled hardened volcanic ash-soil (Cangahua) in Ecuador. Catena 72, 179-190.

Quinn, G.P., Keogh, M.J., 2006. Experimental Design and Data Analysis for Biologists. Cambridge University Press, Cambridge, UK.

Rosenberger, G., Dirksen, G., Grunder, H.-D., Grunert, E., Krause, D., Stober, M., Mack R., 1977. Clinical Examination of Cattle. Verlag Paul Parey, Berlin, DE.

Schulze, R.E., 1997. South African Atlas of Agrohydrology and Climatology. TT82/96 Water Research Commission, Pretoria, RSA.

Snyman, H.A., 1988. Measuring water-use efficiency from rangeland in the Central Grassveld from Evapotranspiration. Water S. A. 14, 153-158.

Snyman, H.A., 2005. Rangeland degradation in a semi-arid South Africa. I. Influence on seasonal root distribution, root/shoot ratios and water-use efficiency. J. Arid Environ. 60, 457-481.

Snyman, H.A., Du Preez, C.C., 2005. Rangeland degradation in a semi-arid South Africa. II. Influence on soil quality. J. Arid Environ. 60, 483-507.

Thurow, T.L., Blackburn, W.H., Taylor, C.A., 1986. Hydrologic characteristics of vegetation types as affected by livestock grazing systems. J. Range Manage. 39, 505-509.

Wang, D., Lowery, B., Norman, J., MacSweeney, K., 1996. Ant burrow effects on water flow and hydraulic properties of Sparta sand. Soil Tillage Res. 37, 83-93.

Waterhouse, D.F., 1974. The biological control of dung. Sci. Am. 230, 101-108.

W.R.B., 1998. World Reference Base for Soil Resources. World Soil Resources Reports, no. 84. FAO, Rome, p. 88. 